SANTOS, Rodrigo Luis dos. Contra o mal que vem do Oriente: o discurso antinipônico no Brasil através das representações imagéticas. Domínios da Imagem, Londrina, v. 12, n. 22, p. 68-89, jan./jun. 2018.

ISSN 2237-9126

Recebido em 8/2/2018 e aprovado em 13/11/2018

\title{
CONTRA O MAL QUE VEM DO ORIENTE: O DISCURSO ANTINIPÔNICO NO BRASIL ATRAVÉS DAS REPRESENTAÇÕES IMAGÉTICAS
}

\section{AGAINST THE EVIL THAT COMES FROM THE EAST: ANTINIPONIC DISCOURSE IN BRAZIL THROUGH IMAGERY REPRESENTATIONS}

Rodrigo Luis dos Santos ${ }^{\bullet}$

Resumo: Este artigo tem por objetivo analisar os discursos contrários a presença de imigrantes no Brasil entre os anos de 1908 e 1945, construídos através de representações imagéticas, publicadas em revistas ilustradas de ordem satírica e obras vinculadas diretamente com a campanha antinipônica. Para tanto, iremos analisar caricaturas publicadas nas revistas $O$ Malho e Fon-Fon, assim como no livro A ofensiva japonesa no Brasil. No caso das revistas, foram lançadas na fase inicial da vinda destes imigrantes para 0 país, em 1908, enquanto no livro, as imagens datam de 1942, no ápice da Segunda Guerra Mundial e do Estado Novo no Brasil.

Palavras-chave: Imagens. Imigração Nipônica. Xenofobia.

Abstract: This article aims to analyze discourses against the presence of immigrants in Brazil between the years 1908 and 1945, constructed through imagery representations, published in illustrated magazines of satirical order and works directly linked to the anti - Nazi campaign. For that, we will analyze caricatures published in the magazines $O$ Malho and Fon-Fon, as well as in the book The Japanese Offensive in Brazil. In the case of the magazines, they were launched in the initial phase of the arrival of these immigrants to the country in 1908, while in the book, the images date back to 1942 at the height of World War II and the Estado Novo in Brazil.

Keywords: Images. Nipponese Immigration. Xenophobia.

\footnotetext{
- Doutorando em História (bolsista PROSUC/CAPES) pela Universidade do Vale do Rio dos Sinos - UNISINOS, São Leopoldo/RS. Mestre e graduado em História pela mesma instituição. Contato: rluis.historia@gmail.com.
} 
SANTOS, Rodrigo Luis dos. Contra o mal que vem do Oriente: o discurso antinipônico no Brasil através das representações imagéticas. Domínios da Imagem, Londrina, v. 12, n. 22, p. 68-89, jan./jun. 2018.

ISSN 2237-9126

\section{Introdução}

Há um ditado popular afirmando que "uma imagem vale mais que mil palavras". Evidentemente, existe um certo exagero nesta enunciação, mas é inegável o poder que a imagem, em seus múltiplos tipos e suportes, exerce sobre o ser humano. Ela representa, em muitos casos, expressões que não se emolduram meramente pelo meio escrito ou falado, ou potencializam discursos, ideias, sentimentos. Desta forma, a imagem é parte fundamental na materialização cultural dos grupos sociais humanos ao longo da História. Desde períodos antiquíssimos até a contemporaneidade, esse conjunto de traços, cores, sentidos e percepções faz parte de nosso viver cotidiano.

Neste artigo, nosso objetivo é analisar a utilização imagética como ferramenta de vinculação ideológica e de manifesto discursivo, adotando um viés sociopolítico. Para tanto, nossa investigação se dará mapeando a construção de representações sobre imigrantes japoneses no Brasil, abarcando o período temporal situado entre 1908 e 1945. A primeira data remete à chegada oficial das primeiras levas imigrantistas nipônicas ao país e, a segunda, ao término da Segunda Guerra Mundial - com o ataque atômico ao Japão - e do período do Estado Novo no Brasil.

\section{Caricaturas e charges: textos e contextos}

No panorama das fontes, os documentos ainda possuem um papel de destaque. Das fontes imagéticas, existe um reconhecimento e tratamentos mais substanciais relacionados com o âmbito das fotografias e do cinema. Contudo, outras tipologias, como as charges e caricaturas, ainda ocupam um espaço secundário - embora com uma curva ascendente nos últimos anos. Todavia, existe um potencial gigantesco que deve ser considerado, tendo em vista o que pode ser apreendido da análise crítica deste tipo de fonte. Isso está no fato de que, assim como qualquer outro documento, nos mais 
SANTOS, Rodrigo Luis dos. Contra o mal que vem do Oriente: o discurso antinipônico no Brasil através das representações imagéticas. Domínios da Imagem, Londrina, v. 12, n. 22, p. 68-89, jan./jun. 2018.

ISSN 2237-9126

variados suportes, as caricaturas e charges são frutos visíveis de elementos intrínsecos, relacionados com as intenções, percepções e subjetividades do autor, e extrínsecos, capitalizando fatos, contextos e conjecturas da multiplicidade dos meios sóciopolíticos e culturais. Nessa perspectiva,

[...] as caricaturas e charges políticas de nossas pesquisas são fruto do trabalho de artistas engajados, simpatizantes de um projeto político (ou pertencente a um partido, como no caso do partido comunista). Em realidade, por estarem presentes em um periódico politicamente engajado, seus trabalhos artísticos só poderiam seguir a sua orientação. Mesmo em outros periódicos (jornais ou revistas) dito burgueses, as caricaturas e as charges expressavam o ponto de vista tomado por estes. A liberdade pode se tornar meramente simbólica (GAWRYSZEWSKI, 2008, p. 15).

As imagens escolhidas foram publicadas em diferentes meios, mas de forma especial, em revistas satíricas e obras especificamente de campanha contrária a presença japonesa em solo brasileiro, apontando-a como um grave perigo para a nação. Esteticamente, estas imagens se enquadram em uma perspectiva caricatural. O termo caricatura tem como base a expressão italiana caricare, que pode ser traduzida como carregar, exagerar. Essa expressão imagética surgiu em Bolonha, no século XVII, tendo como um de seus primeiros expoentes o pintor Agostino Carrari, que elaborou imagens mais exageradas dos tipos humanos que via no cotidiano de sua cidade. Outro nome importante foi Pier Leone Ghezzi, que se dedicou quase que exclusivamente a esse tipo de representação artística.

Sobre a definição conceitual de caricatura, Joaquim da Fonseca entende que a mesma 
SANTOS, Rodrigo Luis dos. Contra o mal que vem do Oriente: o discurso antinipônico no Brasil através das representações imagéticas. Domínios da Imagem, Londrina, v. 12, n. 22, p. 68-89, jan./jun. 2018.

ISSN 2237-9126

[...] é a representação plástica ou gráfica de uma pessoa, tipo, ação ou idéia interpretada voluntariamente de forma distorcida sob seu aspecto ridículo ou grotesco. É um desenho que, pelo traço, pela seleção criteriosa de detalhes, acentua ou revela certos aspectos ridículos de uma pessoa ou de um fato. Na maioria das vezes uma característica saliente é apanhada ou exagerada (FONSECA, 1999, p. 17).

Outra definição, intimamente ligada com nosso enfoque analítico, que são os usos políticos da imagem como veículo difusor de ideias, é dada por J. Enrique Malagón, quando afirma que a caricatura é

una imagen generalmente unida al grabado o a cualquer outro tipo de reproducción masiva que consiste en una reducción o síntesis visual por médio de líneas de la persona u objeto que se representa; en donde la idea de agresividade, degradación, exageración, juego, fantasía o vertiente humorística están en mayor o menor medida patentes con el fin de crear un código por el que se pueda representar una opinión, una crítica, o en definitiva un contenido que si quiere dar a conocer en relación a una persona, una idea o un situación determinada (MALAGÓN, 2002, p.13).

As imagens que escolhemos expressam, em diferentes graus, o sentido de crítica ao grupo étnico nipônico, selecionando elementos relacionados com o fenótipo, traços culturais ou direcionamentos políticos, adequando-as com uma representação de exotismo, estranhamento, ressaltando as diferenças e inferiorizando-os em relação ao brasileiros e aos ocidentais. Em suma, a partir de uma narrativa visual, se buscou potencializar os efeitos de ideias e discursos que já circulavam no Brasil desde o século XIX acerca do povo japonês, mesmo havendo, em determinados momentos, ações de ordem política que viam nesse grupo uma ferramenta econômica satisfatória para os interesses brasileiros, como o trabalho nas plantações de café da região Sudeste, notadamente no estado de São Paulo.

Quando adentramos na esfera das representações no meio social, é preciso compreender que estas fazem parte de um jogo de poderes e 
SANTOS, Rodrigo Luis dos. Contra o mal que vem do Oriente: o discurso antinipônico no Brasil através das representações imagéticas. Domínios da Imagem, Londrina, v. 12, n. 22, p. 68-89, jan./jun. 2018.

ISSN 2237-9126

escalas, onde se tentam sedimentar visões de um grupo sobre si e sobre os demais. Assim, o que se pretende representar pode ser algo que é perceptível, conectado com o real, ou por outro lado, elementos que são produzidos por meio de distorções, mas que passam a circular no ambiente, permeando o imaginário coletivo. Sobre esse fenômeno, Carlo Ginzburg esclarece que

por um lado, a "representação" faz as vezes da realidade representada e, portanto, evoca a ausência; por outro, torna visível a realidade representada e, portanto, sugere a presença. Mas a contraposição poderia ser facilmente invertida: no primeiro caso, a representação é presente, ainda que como sucedâneo; no segundo, ela acaba remetendo, por contraste, à realidade ausente que pretende representar (GINZBURG, 2001, p. 85).

As representações de si e dos outros, conforme Chartier (1990), são signos importantes para a percepção dos contrastes e aproximações entre os diferentes sujeitos sociais. No caso, ao abordarmos as representações incutidas aos sujeitos de origem nipônica, também buscamos estabelecer um panorama do imaginário social edificado sobre os mesmos.

A partir deste panorama, contemplando também alguns elementos teóricos pertinentes ao processo de crítica imagética e os sentidos que estas possuem relacionadas ao campo das representações e imaginação social, iremos contemplar, sequencialmente, a análise de algumas caricaturas publicadas em diferentes meios, de forma especial as revistas ilustradas voltadas para o humor e a sátira, como foram os casos de O Malho e Fon-Fon, e obras objetivamente antinipônicas, como o livro A ofensiva Japonesa no Brasil, cuja segunda edição data de 1942.

Talvez caiba aqui descrever um pouco os caminhos da pesquisa, ou seja, as razões que estiveram presentes para a escolha desta abordagem temática, assim como das imagens escolhidas para apreciação. Inicialmente, destacamos que o tema concernente sobre a imigração japonesa para o Brasil é algo sobre o qual recentemente temos pesquisado. Durante nossa 
SANTOS, Rodrigo Luis dos. Contra o mal que vem do Oriente: o discurso antinipônico no Brasil através das representações imagéticas. Domínios da Imagem, Londrina, v. 12, n. 22, p. 68-89, jan./jun. 2018.

ISSN 2237-9126

trajetória de investigação historiográfica, a abordagem principal tem sido o contexto social, político e religioso envolvendo imigrantes alemães e descendentes no Sul do Brasil, especialmente durante a Primeira República (1889-1930) e Era Vargas (1930-1945). Mais recentemente, nas pesquisas relacionadas com o doutoramento em História, as lentes foram focadas na trajetória política e intelectual de Carlos de Souza Moraes, advogado, escritos e político sul-rio-grandense, especialmente nos aspectos vinculados com a imigração e a difusão de ideias nacionalistas. Deste modo, as percepções e argumentações antinipônicas surgiram como um elemento correlato, do qual optamos por iniciar uma exploração mais aprofundada.

A escolha da imagens que serão sopesadas ao longo deste artigo foi suscitada a partir da capa e contracapa da obra de Moraes contra a imigração nipônica, o livro A ofensiva japonesa no Brasil. De certa foram, as imagens escolhidas oferecem um impacto ao leitor. Neste sentido, surgiu a intenção de explorar essa possibilidade analítica, que são os recursos instrumentais imagéticos. Com essa intenção, iniciamos uma busca por outras imagens que dessem uma dimensão do discurso antinipônicos no Brasil ao longo das primeiras décadas do século XX. Através das leituras para embasamento da pesquisa, tivemos indicações que as revistas $O$ Malho, FonFon, Careta, entre algumas outras, publicaram charges e caricaturas que evidenciavam um corolário de desconfiança, preconceito e contrariedade à presença japonesa no território brasileiro.

De antemão, um aspecto importante que foi possível apurar é o fato de que, desde os primeiros tempos da chegada dos japoneses ao Brasil, as revistas que possuíam um discurso mais satírico, como as anteriormente referidas, adotaram um tom fortemente oposicionista e aviltante contra este grupo étnico. E essa tonalidade vai ganhando cores mais densas, na medida em que as ideias e discursos nacionalistas e eugenistas ganham mais ênfase entre intelectuais e políticos, especialmente a partir dos anos 1920. Assim, o 
SANTOS, Rodrigo Luis dos. Contra o mal que vem do Oriente: o discurso antinipônico no Brasil através das representações imagéticas. Domínios da Imagem, Londrina, v. 12, n. 22, p. 68-89, jan./jun. 2018.

ISSN 2237-9126

recorte temporal escolhido - em torno de trinta e sete anos - evidencia a continuidade destas manifestações.

Metodologicamente, nos apropriamos nas considerações de Ana Maria Mavad para empreender o processo investigativo das imagens por nós elencadas. Para esta pesquisadora, o exercício crítico de análise imagético

\begin{abstract}
engendra alguns desdobramentos teórico-metodológicos, dentre os quais realçamos os processos de produção de sentido na sociedade contemporânea, com destaque para o papel desempenhado pela tecnologia; a definição do circuito social da produção de imagens técnicas, enfatizando a historicidade dos regimes visuais; o papel dos sujeitos sociais como mediadores da produção cultural, compreendendo que a relação entre produtores e receptores de imagens se traduz numa negociação de sentidos e significados; e a capacidade narrativa das imagens técnicas, discutindo-se aí a dimensão temporal das imagens, os elementos definidores de uma linguagem eminentemente visual e por fim 0 diálogo estabelecido entre imagens técnicas e outros textos, tanto de caráter verbal como não-verbal, a partir do princípio de intertextualidade (MAUAD, 2005, p. 134).
\end{abstract}

Embasados nesse roteiro, buscaremos, de forma prática e dentro das possibilidades cabíveis, enfocar a apreensão das mensagens que as caricaturas e charges por nós escolhidas tentam transmitir ao observador destacando que a análise do pesquisador também é marcada pela subjetividade e pelo escopo referencial e historiográfico que possui. Do mesmo modo, enquadrar essas imagens em seu contexto de elaboração e difusão, assim como a historicidade das obras em que foram publicadas. A partir deste panorama, tentaremos trazer subsídios que colaborem com a historiografia recente acerca da questão da imigração japonesa no Brasil e sua representação dentro do contexto de ascensão do nacionalismo e das ideias autoritárias, entre as décadas de 1920 e 1940. 
SANTOS, Rodrigo Luis dos. Contra o mal que vem do Oriente: o discurso antinipônico no Brasil através das representações imagéticas. Domínios da Imagem, Londrina, v. 12, n. 22, p. 68-89, jan./jun. 2018.

ISSN 2237-9126

\section{Exóticos e perigosos: imigrantes japoneses e a oposição através das imagens}

O início oficial da imigração japonesa para o Brasil teve início em 18 de junho de 1908, com a chegada dos primeiros nipônicos, trazidos pelo navio Kasato Maru, desembarcando no Porto de Santos. Estes primeiros imigrantes foram deslocados para o trabalho em fazendas de café no interior do estado de São Paulo. Contudo, uma aproximação diplomática entre Brasil e Japão começou a ganhar mais corpo já no ultimo quartel do século XIX, quando iniciaram as primeiras tratativas para efetivar a vinda de japoneses para 0 Brasil. Mas, a questão apresentava, entre diplomatas, políticos e intelectuais, visões dicotômicas: alguns defendiam a imigração, enquanto outros, por seu turno, alegavam que tal fato seria extremamente prejudicial para o Brasil, evocando as diferenças raciais, biológicas e culturais para referendar sua opinião contrária em ralação a esta política imigratória. Deste modo, apenas no final da primeira década do século XX que se deu, oficialmente, a efetivação do desembarque nipônico em terras brasileiras.

$\mathrm{Na}$ edição de número 325 da revista $\bigcirc$ Malhol, datada de 05 de dezembro de 1908, é publicada uma crítica, em forma de charge, sobre a chegada de imigrantes nipônicos em São Paulo. No primeiro quadro da charge, chamava-se a atenção para os interesses meramente econômicos dos cafeicultores paulistas, pouco interessados nas consequências culturais, sociais e biológicas da presença japonesa no país. A imagem é acrescida dos dizeres: "O governo de São Paulo é teimoso. Após o insucesso da primeira imigração japonesa, contratou 3.000 amarelos. Teima, pois em dotar o Brasil com uma raça diametralmente oposta à nossa" (O MALHO, 1908, p. 10).

\footnotetext{
1 A revista $O$ Malho, de cunho humorístico, foi fundada no Rio de Janeiro em 1902, por Luís Bartolomeu de Souza e Silva e Crispim do Amaral. Era conhecida por satirizar fatos políticos e sociais. Reativada em 1935, fez publicações até 1954, quando foi definitivamente fechada. Suas edições foram digitalizadas pela Casa de Rui Barbosa, sendo seu acesso possível através do seguinte endereço eletrônico: http://www.casarvibarbosa.gov.br/omalho/.
} 
SANTOS, Rodrigo Luis dos. Contra o mal que vem do Oriente: o discurso antinipônico no Brasil através das representações imagéticas. Domínios da Imagem, Londrina, v. 12, n. 22, p. 68-89, jan./jun. 2018.

ISSN 2237-9126

Figura 01 - Sátira sobre a Imigração Japonesa na Revista O Malho

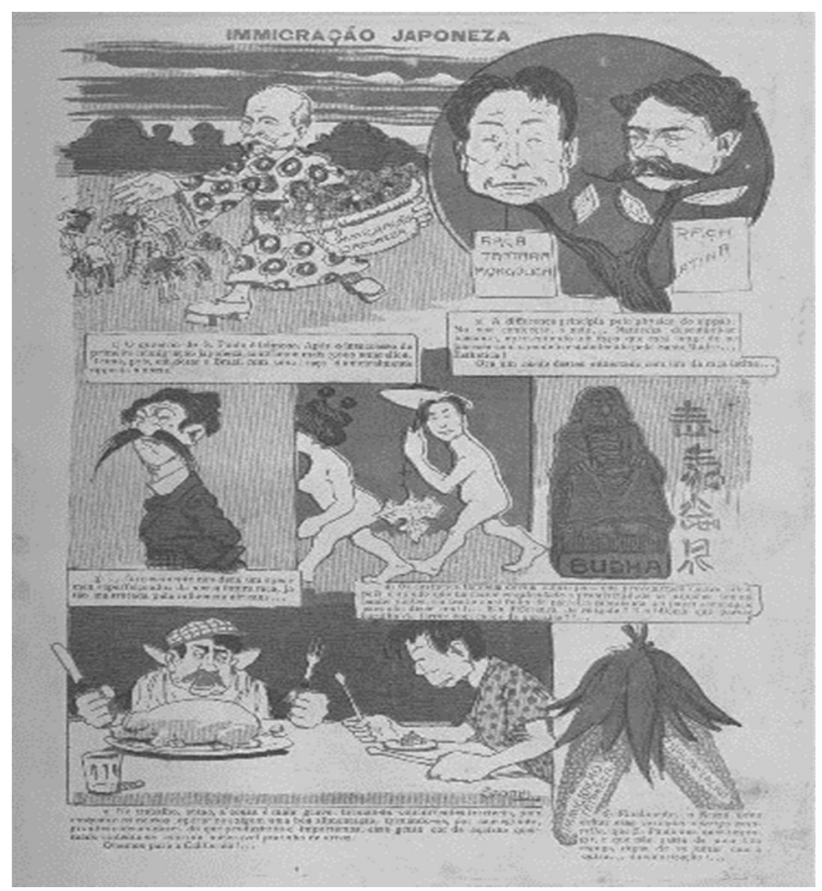

Fonte: Casa de Rui Barbosa. Disponível em:

http://www.casaruibarbosa.gov.br/omalho/revista.asp? rev=325\&ano=1908\&

$$
\mathrm{pag}=\mathrm{cl}
$$

Sobre a autoria da charge, infelizmente não encontramos maiores detalhes. Mas, a partir da leitura de obras como História da Imprensa no Brasil, organizada por Ana Luiza Martins e Tânia de Luca (2008), foi possível apurar que a revista $O$ Malho, após ser empastelada em fechada em 1930, por ter feito oposição a Aliança Liberal (e que chegou ao poder por meio de um golpe de Estado em outubro daquele mesmo ano), ao ser reaberta, em 1935, adotou um tom menos crítico ao governo de Vargas. Em 1937, com o Estado Novo, o campo editorial do periódico converge em seu escopo para a defesa dos aspectos centrais defendidos pelo novo sistema sociopolítico e cultural, como a defesa dos interesses pátrios e da nacionalização dos estrangeiros. Essa aproximação com o governo ditatorial varguista fica mais clara quando, a partir de 1937, a Sociedade Anônima "O Malho", responsável pela revista homônima, passa a editar o periódico Ilustração Brasileira (até 1944), utilizada 
SANTOS, Rodrigo Luis dos. Contra o mal que vem do Oriente: o discurso antinipônico no Brasil através das representações imagéticas. Domínios da Imagem, Londrina, v. 12, n. 22, p. 68-89, jan./jun. 2018.

ISSN 2237-9126

amplamente, conforme Geanne Silva (2008), como instrumento panfletário da ideologia estadonovista. Mas, ao analisarmos o conteúdo das charges relacionadas com os imigrantes, especialmente os japoneses, desde 1908 quase três décadas antes da ascensão do regime do Estado Novo -, é nítido que já existia um alinhamento com as representações e discursos que se potencializaram e se efetivaram como política de estado entre 1937 e 1945. Neste sentido, o conteúdo panfletário antinipônico da revista O Malho estava em diálogo convergente com a ideologia que se perpetuara durante a ditadura de Getúlio Vargas.

Nos tópicos seguintes, tanto através das imagens utilizadas quando nos pequenos textos que as acompanham, são elencados motivos para demonstrar que a imigração nipônica não representa algo positivo para o Brasil. Esses discursos estão revestidos de uma conotação xenófoba, elegem especialmente padrões estéticos e culturais para reforçar seus argumentos junto aos leitores da revista. Enquanto expressões caricaturais, elas exageram nos traços físicos, como, por exemplo, alegando que os japoneses eram modelos antiestéticos - no segundo quadro, o termo carão é utilizado de forma pejorativa - contrastando com os latinos. Além disso, a abordagem da revista apregoa que uma miscigenação entre japoneses e brasileiros maltrataria ainda mais a raça nacional, a exemplo do que ocorre em decorrência da presença africana no país, também referindo-se a esse grupo social de forma inferiorizante. Por fim, utilizam-se argumentos de ordem cultural, estabelecendo uma linha de pensamento que atribui aos nipônicos hábitos imorais e promíscuos, assim como uma língua ininteligível e religião deturpada.

Alguns meses antes desta publicação, em janeiro de 1908, foi a revista Fon-Fon ${ }^{2}$ que usou suas páginas para construir uma visão acerca do Japão e

\footnotetext{
2 A fundação da revista Fon-Fon, onomatopeia vinculada com o som produzido pela buzina dos automóveis, ocorreu em 1907, no Rio de Janeiro, sendo editada até 1958. Um de seus fundadores foi o escritor Luís Gonzaga Duque Estrada. Enfocava principalmente costumes e fatos do cotidiano. A ilustrações eram um dos seus pontos marcantes, tendo entre seus
} 
SANTOS, Rodrigo Luis dos. Contra o mal que vem do Oriente: o discurso antinipônico no Brasil através das representações imagéticas. Domínios da Imagem, Londrina, v. 12, n. 22, p. 68-89, jan./jun. 2018.

ISSN 2237-9126

sua relação com o Ocidente, de forma especial com o Estados Unidos, que começava a despontar como potência econômica em nível mundial. A imagem tem como autor o caricaturista, ilustrador, pintor e professor Calixto Cordeiro (1877-1957), mais conhecido pelo pseudônimo "K. Lixto". Durante o período em que atuou na Fon-Fon, dedicou-se a representar o cotidiano político, tanto em nível nacional quanto mundial. Das personalidade nacionais, seus principais "alvos" foram o marechal Hermes da Fonseca, presidente do Brasil entre 1910 e 1914, e o senador gaúcho José Gomes Pinheiro Machado, assassinado no Rio de Janeiro em 1915.

Figura 02 - Caricatura sobre Japão e a América

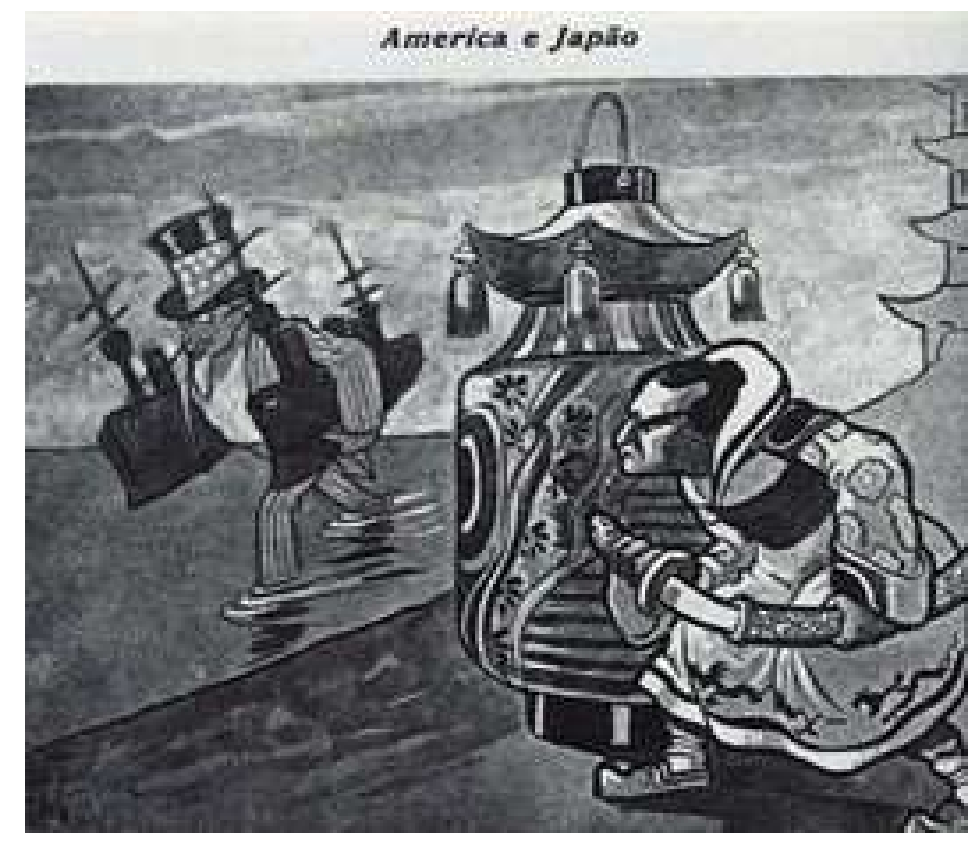

Fonte: Disponível em:

http://objdigital.bn.br/acervo_digital/div_periodicos/fonfon/fonfon_1908/fonf on_1908_042.pdf.

colaboradores inclusive pintores de renome, como Di Cavalvanti. Dentre os ilustradores que ficaram conhecidos através de seu trabalho na revista estão Raul Pederneiras, K. Lixto, J. Carlos e Nair de Tefé. Edições digitalizadas da revista, datadas entre 1907 e 1945, podem ser acessadas através do endereço eletrônico: http://objdigital.bn.br/acervo_digital/div_periodicos/fonfon/fonfon_anos.htm. 
SANTOS, Rodrigo Luis dos. Contra o mal que vem do Oriente: o discurso antinipônico no Brasil através das representações imagéticas. Domínios da Imagem, Londrina, v. 12, n. 22, p. 68-89, jan./jun. 2018.

ISSN 2237-9126

A representação do Japão se baseia em uma alusão aos trajes tradicionais, remetendo ao passado, destoando com um país que, embora mantenedor de preceitos culturais ancestrais, passava por uma fase expansionista. Ao mesmo tempo, destaca-se a postura combativa e traiçoeira, pronto para o ataque surpresa e violenta ao inimigo, no caso, os Estados Unidos, também em ampla expansão. O estilo combativo também expressa a crescente militarização japonesa, envolvido em dois conflitos bélicos entre 1894 e 1905: as guerras sino-japonesa (1894-1895) e russojaponesa (1904-1905), fatos que enquadram-se na política de expansão e imposição em esfera global adotada pelo Japão a partir da ascensão do imperador Meiji, em 1867, governando até sua morte, em 1912. Entrementes, a imagem expressa a necessidade de vigilância em relação ao império oriental, tendo em vista sua política considerada predatória. E a presença de imigrantes japoneses no Brasil poderia colocar o país como alvo das investidas nipônicas.

Se naqueles primeiros anos da presença japonesa no Brasil o discurso materializado em textos e imagens se baseava em indícios de um país que estava se tornando uma potência, nas três décadas seguintes eram subsidiadas por uma força militar já consolidada no Japão, embora este passasse por problemas sociais - a explosão demográfica - e econômicos expressivos, especialmente após a Crise de 1929. O excedente populacional colocava o país mergulhado em carestia, fome e uma crescente miserabilidade. Como forma de resolução destes problemas, grupos ultranacionalistas, ligados aos setores militares passaram a defender a expansão territorial através do uso bélico.

Diante da adoção de novas medidas expansionistas, o Japão segue o exemplo de outras potências ocidentais. $\bigcirc$ alvo inicial das investidas nipônicas foi a China, obrigada a firmar acordos políticos e econômicos que the prejudicavam de forma significativa. O passo seguinte foi a invasão da Manchúria, vasta região localizada no leste asiático - que atualmente inclui o 
SANTOS, Rodrigo Luis dos. Contra o mal que vem do Oriente: o discurso antinipônico no Brasil através das representações imagéticas. Domínios da Imagem, Londrina, v. 12, n. 22, p. 68-89, jan./jun. 2018.

ISSN 2237-9126

extremo nordeste da China, também chamada Manchúria Interior, e uma parte da Sibéria, na Rússia. Essa região foi transformada em um estado fantoche japonês. Ainda em 1931, a força aérea japonesa bombardearam Shangai. Como consequência da invasão e tomada da Manchúria, o Japão passa a receber severas críticas por parte da Liga das Nações. Em consequência, o país retira-se da entidade em 1933.

A etapa seguinte do projeto imperialista japonês na Ásia ocorre em 1937, quando se deflagra a segunda Guerra Sino-Japonesa, passando as tropas nipônicas a ocuparem praticamente toda a extensão litorânea chinesa. Além disso, as práticas de atrocidades praticadas pelos soldados japoneses ganham destaque internacional. O conflito se estendeu até 1945 , concomitante com a participação do Japão na Segunda Guerra Mundial.

Em 1940, o Japão ocupou o Vietnã, além de assinar pactos de colaboração com a Alemanha e Itália. Essas medidas colocaram o país em rota de colisão com os interesses dos Estados Unidos e Inglaterra, cuja represaria se deu através de um boicote no abastecimento de petróleo. A reação japonesa se deu através da apropriação de refinarias na Indonésia.

Essa conjuntura militar e política japonesa a partir de 1930 serviu, entre intelectuais e políticos brasileiros, como plataforma para a adoção de discursos cada vez mais virulentos contra o país, seu projeto imperialista e a presença de imigrantes deste grupo étnico no Brasil. Um dos grupos mais incisivos na campanha antinipônica foi a Sociedade dos Amigos de Alberto Torres, entidade nacionalista criada em 1932, com sede no Rio de Janeiro, reunindo figuras de diferentes áreas de atuação, como jornalistas, empresários, militares, médicos, advogados, cientistas sociais, antropólogos, entre outros.

A agenda antinipônica da Sociedade dos Amigos de Alberto Torres não ficaram restritas ao pronunciamentos, palestras, artigos e publicação de livros. Ela também galgou uma participação política mais efetiva, como foi o caso da Assembleia Nacional Constituinte de 1933-1934. Foram eleitos deputados 
SANTOS, Rodrigo Luis dos. Contra o mal que vem do Oriente: o discurso antinipônico no Brasil através das representações imagéticas. Domínios da Imagem, Londrina, v. 12, n. 22, p. 68-89, jan./jun. 2018.

ISSN 2237-9126

Miguel Couto e Antônio Xavier de Oliveira, membros ativos da entidade, que se empenharam arduamente para a aprovação de leis que impedissem a entrada de japoneses no Brasil. Os principais argumentos utilizados eram estes imigrantes poderiam colocar o país na mira de ações por parte do Império Japonês, tendo em vista a voracidade expansionista nipônica. Criticavam, também, o enquistamento que esses imigrantes formam nos lugares por eles colonizados - impedindo sua assimilação ao país, argumento também utilizado contra alemães, poloneses, etc - assim como o papel exercido pelas companhias japonesas de colonização, denunciando que estas funcionariam como uma espécie de tentáculo do governo japonês no Brasil, sendo responsáveis pela contratação dos imigrantes, colonização da terra, produção e exportação e, fato mais preocupante, de propalar e fiscalizar a obediência religiosa ou jurídica que esses imigrantes devotariam a seus líderes no Japão, especialmente o imperador e as altas autoridades militares.

Com a implantação do Estado Novo, em novembro de 1937, e a deflagração do projeto de nacionalização e desbaratamento dos considerados quistos étnicos, a propaganda e a participação de membros da Sociedade dos Amigos de Alberto Torres nesse projeto ganhou novo impulso. Por não ser considerada uma agremiação partidária, e por ter integrantes vinculados ao governo de Getúlio Vargas - como foi o caso de Oliveira Vianna, Dulphe Pinheiro Machado, entre outros -, a entidade continuou atuando com liberdade ao longo do período estadonovista. Núcleos estaduais haviam sido organizados em diferentes unidades da federação. Um destes núcleos foi fundado em 1936 no Rio Grande do Sul, tendo como fundador e primeiro presidente Carlos de Souza Moraes, que atuou entre 1937 e 1944 como secretário da Prefeitura Municipal de São Leopoldo - cidade conhecida como berço da imigração alemã no Brasil -, diretor de Instrução Pública e diretor do jornal oficial da municipalidade. Entre 1944 e 1945, quando chegou ao fim a ditadura varguista, exerceu o cargo de prefeito leopoldense. Este mesmo Carlos de Souza Moraes foi autor do livro A ofensiva 
SANTOS, Rodrigo Luis dos. Contra o mal que vem do Oriente: o discurso antinipônico no Brasil através das representações imagéticas. Domínios da Imagem, Londrina, v. 12, n. 22, p. 68-89, jan./jun. 2018.

ISSN 2237-9126

japonesa no Brasil, lança primeiramente em 1937, recebendo uma segunda edição, revisada, ampliada e com incremento imagético, em 1942, pela Editora do Globo.

No dia 7 de dezembro de 1941, as forças militares japonesas empreenderam um ataque surpresa À base estadunidense de Pearl Harbor, localizada no Havaí. Foi essa ação do Japão que definiu a entrada dos Estados Unidos na Segunda Guerra Mundial, ao lado da Inglaterra e União Soviética. Além do ataque contra Pearl Harbor, outras ações ocorreram no Pacífico. Ao longo de 1941, as tropas imperiais nipônicas ampliaram o controle sobre quase a totalidade do Pacífico e do Sudeste Asiático.

Esse ocorrido foi utilizado como propaganda para A ofensiva japonesa no Brasil, enfatizando que as constatações e denúncias nele contidas não se tratavam apenas de formulações pautadas em possibilidades, mas em fatos concretos, que evidenciavam o perigo da presença de imigrantes japoneses em solo brasileiro, sobretudo em um momento em que o país se alinhava politicamente ao Estados Unidos, que declarara guerra aos países do Eixo Alemanha, Itália e Japão.

Mas a propaganda em relação ao livro não se deteve apenas em utilizar Pearl Harbor como vitrine. Foram adotadas diferentes medidas difusoras e pedagógicas para a circulação da obra e do objetivo a qual pleiteava: apresentar o imigrante japonês como um inimigo em potencial, que precisava ser combatido patrioticamente, para o bem do Brasil. E uma destas ações está relacionada com as imagens utilizadas, especialmente na capa e na contracapa da publicação. Suas escolhas já denotam uma mensagem que pretendia-se passar e incutir no imaginário coletivo. Sobre esse aspecto - a elaboração de uma percepção e mentalidade coletiva sobre algo - Baczko (1985, p. 306) postula que somente é possível comungar ou comunicar entre os homens através de símbolos exteriores aos estados mentais individuais, através de signos posteriormente concebidos como realidades. Assim, é concebido todo um aparato visando embasar as representações elaboradas 
SANTOS, Rodrigo Luis dos. Contra o mal que vem do Oriente: o discurso antinipônico no Brasil através das representações imagéticas. Domínios da Imagem, Londrina, $v$. 12, n. 22, p. 68-89, jan./jun. 2018.

ISSN 2237-9126

e sua difusão. E as imagens estão do rol deste aparato. E delas iremos proceder a análise.

Ao delinearmos os detalhes contidos nos elementos constantes na capa de A ofensiva japonesa no Brasil, fica evidenciada a tentativa de estereotipar os japoneses como elementos estranhos, deformados, esquisitos, tanto no ponto de vista físico quanto moral e culturalmente. Podemos perceber que, para além destes enquadramentos, a imagem também apregoa a representação de um caráter cínico, malicioso e, no caso feminino, libidinoso, voltado muito mais para a sexualidade - expressa na criação imagética de uma gueixa.

Sobre o elemento feminino, Rogério Dezem, em sua obra Matizes do "amarelo" (2005, p. 265-266), enfatiza que desde, pelo menos, 1904, a imprensa brasileira repercutia a imagem de desvalorização da mulher japonesa, vista como um elemento inferior, um objeto dentro de um sistema patriarcal, além de ser desprovida de valores patrióticos de características como a indolência e a incapacidade. Retomando a análise da imagem, ao instituir a figura feminina com conotações sexuais e certas deformações morais, também se faz referência ao papel da mulher japonesa no plano expansionista imperial: satisfação dos impulsos e prazeres dos combatentes e, ao mesmo tempo, ser instrumento de produção demográfica, colaborando para o aumento do efetivo de soldados japoneses.

Ainda sobre a representação feminina, o livro Bodies of memory (2000), de Yoshikuni Igarashi, demonstra que, mesmo após o fim da Segunda Guerra Mundial, a figura da mulher continuou sendo adjetivada com conotações negativas, tanto internamente no Japão, como pelas formas militares vencedoras do conflito, especialmente os Estados Unidos. Nesta assertiva, o Japão, que saíra derrotado da guerra, era comparado com uma mulher, incapaz e fragilizada, que somente com a presença viril e civilizada ocidental, poderia reerguer-se. E essa força ocidental, de perfil masculinizado, era a 
SANTOS, Rodrigo Luis dos. Contra o mal que vem do Oriente: o discurso antinipônico no Brasil através das representações imagéticas. Domínios da Imagem, Londrina, v. 12, n. 22, p. 68-89, jan./jun. 2018.

ISSN 2237-9126

estadunidense, capitaneada pelo general Douglas MacArthur, comandante das Forças Aliadas no Japão.

O objetivo central da escolha dessa imagem para a capa do livro assim como a da contracapa - é já causar um efeito didático no imaginário do leitor, conduzindo-o para, a partir da leitura do conteúdo da obra, qualificar a população japonesa com os adjetivos de estranhamento e exotismo que estão impregnados ao longo do livro, por meio da escrita, por meio do recurso caricatural. Na capa, os personagens escolhidos fazem parte do meio popular - mulheres, jovens, idosos. A contracapa, por sua vez, se concentra em personagens relacionados com o ambiente militar e político do Império do Japão.

Figura 03 - Capa do livro A ofensiva japonesa no Brasil

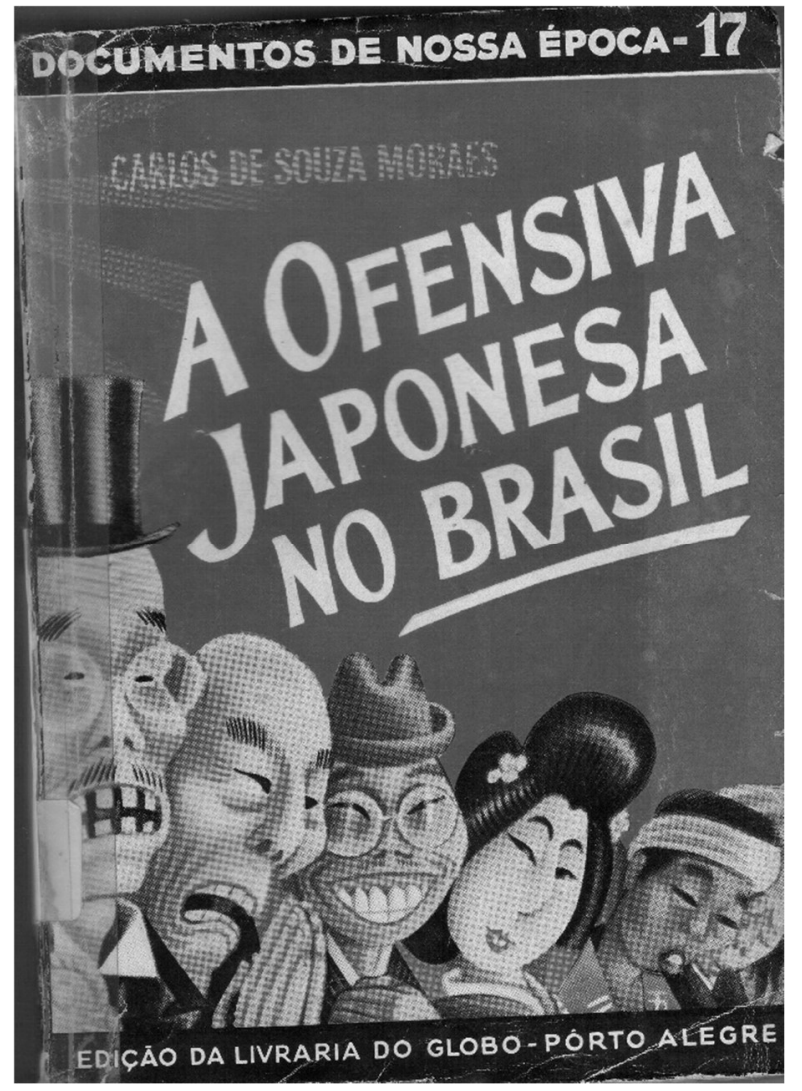

Fonte: Exemplar pertencente à Biblioteca do Museu Histórico Visconde de São Leopoldo 
SANTOS, Rodrigo Luis dos. Contra o mal que vem do Oriente: o discurso antinipônico no Brasil através das representações imagéticas. Domínios da Imagem, Londrina, v. 12, n. 22, p. 68-89, jan./jun. 2018.

ISSN 2237-9126

As figuras principais satirizadas na contracapa do livro são, da esquerda para a direita, o almirante Isoroku Yamamoto, comandante da Marinha japonesa e idealizador do ataque à base estadunidense de Pearl Harbor; o general Hideki Tojo, primeiro-ministro do Japão entre 1941 e 1944 e, mais ao fundo, almirante Chuichi Nagumo, comandante da esquadra que deflagrou o ataque à Pearl Harbor em 1941. Os três são representados com semblante mais carregado, agressivo, justamente para construir uma imagem de homens perigosos, dispostos a tudo para levar a cabo a política imperialista nipônica. Atrás da figura dos três militares, são acrescentadas labaredas de fogo, como que em um incêndio e, do meio delas, em um círculo luminoso, alusão à bandeira japonesa, está a figura do imperador Hirohito, com uma posição gestual mais satirizada - até podemos dizer, ensandecida - que a de seus comandantes militares. Mas, em linhas gerais, o contexto da imagem aponta para um mesmo foco: evidenciar a nação japonesa como altamente nociva, para o mundo e, dentro da agenda política e ideológica da Sociedade dos Amigos de Alberto Torres, para o Brasil, por conta da presença de imigrantes deste país em território nacional.

Figura 04 - Contracapa do livro A ofensiva japonesa no Brasil

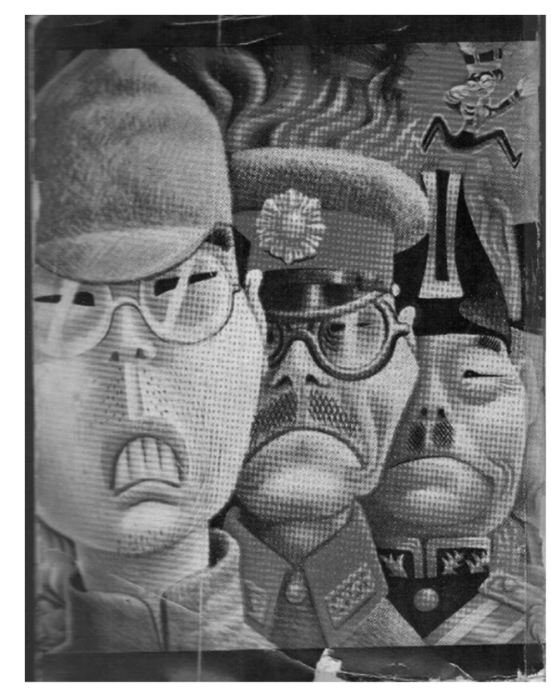

Fonte: Exemplar pertencente à Biblioteca do

Museu Histórico Visconde de São Leopoldo 
SANTOS, Rodrigo Luis dos. Contra o mal que vem do Oriente: o discurso antinipônico no Brasil através das representações imagéticas. Domínios da Imagem, Londrina, v. 12, n. 22, p. 68-89, jan./jun. 2018.

ISSN 2237-9126

Como foi possível ver, a escolha destas imagens tem um caráter notadamente intencional, almejando tanto atrair a atenção do público leitor para o conteúdo do livro, como conduzir o sentido da leitura, incutindo, naquele que lê, a certeza de que os japoneses instalados no Brasil, efetivamente, eram intrusos nefastos e até agentes camuflados, articulados diretamente com o imperialismo nipônico. A representação imagética, deste modo, tem uma abordagem pedagógica, potencializando e sintetizando o ponto nevrálgico da narrativa textual que Carlos de Souza Moraes elabora em A ofensiva japonesa no Brasil: a presença do perigo amarelo.

Em artigo publicado em 2014, Richard Gonçalves André analisa a representação imagética sobre os japoneses incutidas em histórias em quadrinhos, especialmente as relacionadas com o personagem Capitão América, que por sua vez, sintetiza o modelo heroico que os Estados Unidos elaboraram sobre si mesmos. Assim como nas imagens que analisamos neste artigo, aquelas sobre as quais André focaliza sua interpretação utilizam da deformação estereotipada para atribuir um determinado valor - ou a falta destes - para com os japoneses. Se, ao herói, são atribuídas qualidades físicas - beleza, porte e força -, intelectuais e morais, aos inimigos devem ser empregadas conotações desabonadoras, para ampliar o contraste entre estes. Nesse jogo, estão representados os conceitos dicotômicos de bem e mal, civilização e barbárie, liberdade e opressão. Porém, para que um exista, é preciso que o outro coexista. E, na lógica das disputas - reais e simbólicas do poder, a figura do oponente é essencial para consolidar a imagem do vencedor ou embasar determinada concepção ideológica. 
SANTOS, Rodrigo Luis dos. Contra o mal que vem do Oriente: o discurso antinipônico no Brasil através das representações imagéticas. Domínios da Imagem, Londrina, v. 12, n. 22, p. 68-89, jan./jun. 2018.

ISSN 2237-9126

\section{Considerações finais}

Por meio deste artigo, buscamos demonstrar como as produções imagéticas podem ser utilizadas como dispositivos legitimadores de discursos e instrumentos de condicionamento ideológico. Pautamos nosso enfoque na construção de um imaginário coletivo, vinculado com a campanha antinipônica deflagrada no Brasil desde 1908, quando da chegada de forma oficial das primeiras levas de japoneses, tendo seu ponto de maior magnitude nas décadas de 1930 e 1940. A construção de um discurso panfletário e pedagógico, almejando sua absorção pelo meio social, deve lançar mão de múltiplas ferramentas, com a finalidade de alcançar os diferentes meandros que compõe a realidade cultural, política, econômica na qual essa sociedade está arraigada. As imagens, e de forma especial, as caricaturas, permitem um alcance e uma interação com diferentes camadas e grupos sociais. Se pensarmos o Brasil da primeira metade do século XX, com uma população majoritariamente rural e analfabeta, as imagens poderiam obter resultados que, através da escrita, talvez não fossem alcançados.

Por outro lado, as fontes imagéticas constituem um espaço profícuo para a interpretação crítica da mentalidade social, cultural, política, religiosa de uma determinada época. Ao nos dedicarmos às produções imagéticas relacionadas com os grupos imigrantes que adentraram no Brasil desde o século XIX, podemos encontrar a presença marcante de uma alocução xenófoba, baseada, por exemplo, nas teorias raciais que circularam pelo mundo ocidental neste período, como o Darwinismo Social e a Eugênia Racial. E as caricaturas, por seu turno, nos ajudam a perceber como essas relações foram alicerçadas no Brasil, criando um espectro de contraste entre o nós e os outros, estabelecendo uma espécie de fronteira - cultural, identitária, sociopolítica -, que ganhou vulto de política de estado com o nacionalismo do Estado Novo. E, para melhor investigarmos e compreendermos essa fase de nossa história, precisamos utilizar a maior gama de recursos e fontes 
SANTOS, Rodrigo Luis dos. Contra o mal que vem do Oriente: o discurso antinipônico no Brasil através das representações imagéticas. Domínios da Imagem, Londrina, v. 12, n. 22, p. 68-89, jan./jun. 2018.

ISSN 2237-9126

possíveis. E as imagens, em suas diferentes tipologias e materializações, constituem um vasto e fértil campo para se explorar.

\section{Referências}

ANDRÉ, Richard Gonçalves. O perigo amarelo nas histórias em quadrinhos: Capitão América e discurso antinipônico nos Estados Unidos durante a Segunda Guerra Mundial. Domínios da Imagem, Londrina, v. 8, n. 16, p. 113132, jun./dez. 2014.

BACZKO, Bronislaw. Imaginação social. In: ROMANO, Ruggiero (org.). Enciclopédia Einaudi. Lisboa: Imprensa Nacional, Casa da Moeda, 1985.

CAREtA. Rio de Janeiro. Ano V, n. 222, 31 ago. 1912. Disponível em: http://objdigital.bn.br/acervo_digital/div_periodicos/careta/careta_1912/car eta 1912 222.pdf. Acesso em 26 jan. 2018.

CHARTIER, Roger. História da Cultura - entre práticas e representações. Lisboa: Difel, 1990.

DEZEM, Rogério. Matizes do "amarelo": a gênese dos discursos sobre os orientais no Brasil. Série Histórias da Intolerância. São Paulo: Humanitas, 2005. FON-FON. Rio de Janeiro. Ano II, n. 42, 25 jan. 1908. Disponível em: http://objdigital.bn.br/acervo digital/div periodicos/fonfon/fonfon 1908/fonf on_1908_042.pdf. Acesso em 26 jan. 2018.

FONSECA, Joaquim da. Caricatura: A imagem gráfica do humor. Porto Alegre. Artes e ofícios: 1999.

GINZBURG, Carlo. Representação: a idéia, a palavra, a coisa. In: GINZBURG, Carlo. Olhos de madeira: nove reflexões sobre a distância. São Paulo: Companhia das Letras, 2001.

GAWRYSZEWSKI Alberto. Conceito de caricatura: não tem graça nenhuma. Domínios da Imagem, Londrina, v. I, n. 2, p. 7-26, maio 2008.

IGARASHI, Yoshikuni. Bodies of memory. Narratives of war in postwar Japanese culture, 1945-1970. Princeton-NJ, Woodstock-OX: Princeton University Press, 2000.

MALAGÓN, J. Enrique Peláez - El concepto de caricatura como arte en el siglo XIX. In: Sincronía, 2002. 
SANTOS, Rodrigo Luis dos. Contra o mal que vem do Oriente: o discurso antinipônico no Brasil através das representações imagéticas. Domínios da Imagem, Londrina, v. 12, n. 22, p. 68-89, jan./jun. 2018.

ISSN 2237-9126

MARTINS, Ana Luiza; LUCA, Tânia Regina de (orgs.). História da Imprensa no Brasil. São Paulo: Contexto, 2008.

MAUAD, Ana Maria. Na mira do olhar: um exercício de análise da fotografia nas revistas ilustradas cariocas, na primeira metade do século XX. Anais do Museu Paulista. v. 13. n.1. jan.-jun. 2005.

MORAES, Carlos de Souza. A ofensiva japonesa no Brasil: aspecto social, econômico e político da colonização nipônica. Porto Alegre: Livraria do Globo, 1942.

O MALHO. Rio de Janeiro. Ano VII, n. 325, 5 dez. 1908. Disponível em: http://www.casaruibarbosa.gov.br/omalho/revista.asp?rev=325\&ano=1908\& pag $=c$ l, Acesso em 30/09/2017.

SILVA, Geanne Paula de Oliveira. Estado Novo e imprensa ilustrada. propaganda política na revista llustração Brasileira (1935-1944). 2008. 76 f. Monografia (Bacharelado em História). Universidade Federal de Uberlândia, 2008. 